\title{
Essential elements of treatment: A comparative study between European and American therapeutic communities for addiction.
}

Ilse Goethals, Veerle Soyez, Gerald Melnick, George De Leon, Eric Broekaert

\begin{abstract}
The purpose of this study was to investigate whether European and American therapeutic communities (TCs) for addiction, both traditional and modified, share a common perspective on what is essential in treatment using the Survey of Essential Elements Questionnaire (SEEQ). The European sample $(\mathrm{N}=19)$ was gathered in 2009. For the American sample $(\mathrm{N}=19)$ we used previously published research data. Despite comparable perspectives, European traditional TCs $(\mathrm{N}=$ 11) scored significantly higher than their American predecessors $(\mathrm{N}=11)$ on 4 SEEQ domains. Cluster differences were more pronounced in Europe than in America.
\end{abstract}

\section{INTRODUCTION}

The past twenty years, academics have theorized on the similarities and differences between European and American therapeutic communities (TCs) for addiction essentially highlighting the development of two divergent approaches (Broekaert et al. 2000; Broekaert et al., 2004; Broekaert et al., 2007; Haigh \& Lees, 2008; Kennard, 1998). However, more recently it is believed that the TC approach might be generic which implies that, regardless of the changes that have been made to the traditional concept, TCs all over the world will still share a common perspective on what is essential in treatment. Yet, there still is no research available to support these theories.

The aim of the present study is to address this problem by systematically investigating the essential elements of treatment in European and American TCs for addiction. To clarify the context of this study, we will first present a short historical overview on the TC for addiction. For a detailed account on the historical 
background of TCs, see Broekaert et al. (2006a), De Leon (2000), Haigh and Lees (2008), Kennard (1998), Kooyman (2001) and Vandevelde et al. (2004).

In America, the first TC for addictions originated in Synanon in 1958 (Janzen, 2001) and was generally described as a behavioral approach situated in the American humanistic tradition (Broekaert et al., 2006a). Through its affiliation with Alcoholics Anonymous, Synanon emerged as a drug-free self-help group that was run by ex-addicts for ex-addicts (Kennard, 1998). Its method revolved around two central elements: "the Game", later to be rebadged as "the encounter group", and the hierarchical structure of the organization. Since 1965, the drug-free hierarchical model was adopted in 'concept' TCs such as "Daytop", "Phoenix House" and "Odyssey House" (Sugerman, 1974) and ultimately spread throughout the United States, Europe and eventually the rest of the world (Kooyman, 2001; O’Brien and Hennican, 1993).

In Europe, the American "drug-free hierarchical concept-based TC" encountered a longstanding tradition of Milieu-therapy, different schools of therapy and a large diversity of European cultures and ideologies (Broekaert et al., 2006a). That is, the first TCs for addiction in Europe originated, during the late 60s, in special units attached to psychiatric hospitals as well as in psychiatric wards of general hospitals (Kooyman, 1992). Some of these units and wards operated as Maxwell Jones "democratic TCs" since World War II and were theoretically influenced by psycho-analysis, socio-therapy and social learning. While the first European TCs had gathered great expertise in the treatment of personality disorders, they had little knowledge on how to treat drug addiction. This disinterest of psychiatry for drug addiction treatment and the continuously growing addict population, challenged the early pioneers to search for new methods. During the 1970s, professionals from Europe visited American concept-based TCs either with the intent to set up similar organizations in their own countries or to introduce the methodology within their, already existing, democratic TCs (Kooyman, 1992). According to Broekaert et al. (2006a), most European TCs did not just copy the American model but adapted it to their own culture. Unlike their American predecessors, there existed abhorrence to behaviorist interventions such as wearing signs and shaving heads (Broekaert et al., 
2000). European drug-free hierarchical TCs also employed professionals more than ex-addicts (Broekaert et al., 1999), softened the method and thus replaced harsh confrontation in groups by more dialogue (Broekaert et al., 2004).

Both TC traditions flourished until the eighties, but because of the AIDS epidemic, new popular drugs and the growing number of addicts, they lost their influence in favor of methadone treatment and harm reduction programs. Although characterized by local variations, many European governments cut funds and insisted on "new management" with emphasis on efficiency, continuity of care and collaboration between the different treatment systems.

A comparable evolution occurred in America. Changes in healthcare policy and the introduction of health maintenance programs created a demand for reducing the cost of treatment (Melnick \& De Leon, 1999). Most TCs displayed flexibility and modified aspects of their approach to the new management style by creating more complex, but unique treatment settings for different populations and with varied durations of stay (Broekaert, 2006b, De Leon, 1997; 2000; Soyez et al., 2004).

Recent studies have shown positive treatment effects for these 'modified' TC-settings, including TCs for women (Alterman et. al, 2000), prisoners (Knight et al., 1997; Prendergast et al., 2004), adolescents (Jainchill et al., 2005), homeless mentally ill (De Leon et al., 2000), and dual diagnosed clients (Sack et al., 2008). Furthermore, the TC approach, or at least some of its tools, has been successfully implemented in mental health facilities (Broekaert, 2006b).

While these studies clearly underline the strength of the TC approach, the constant adaptations of the traditional TC model have raised some concerns about the quality of the treatment and the effectiveness of the modality (De Leon, 1995b, 2001; Melnick \& De Leon, 1999). To address these concerns, both TC traditions have attempted to define and measure the core TC characteristics.

In America, Melnick and De Leon (1999) developed 'The Survey of Essential Elements Questionnaire (SEEQ)', an instrument describing the TCs' distinctive philosophy and treatment elements. In essence, the 
SEEQ identifies and codifies the core characteristics of a drug-free hierarchical concept based TC approach. Applications of the SEEQ in published research revealed rather promising results. In a first study, the data from a survey of $59 \mathrm{TC}$ programs that were members of the Therapeutic Communities of America (TCA) (Melnick \& De Leon, 1999), demonstrated a high degree of adherence to the essential elements of a TC as outlined by De Leon (1995a; 1995b; 2000) but also showed slight divergence of beliefs between traditional TC programs and modified TC programs. In a second study, using a abbreviated form of SEEQ, the results of 19 American TCs that participated to the Drug Abuse Treatment Outcomes Study (DATOS) supported earlier findings by confirming differences in SEEQ scores between programs previously identified as traditional and modified TCs (Melnick et al., 2000). In a third study, Dye and her colleagues (2009) examined the extent to which modified TCs were able to retain the underlying core technology of the TC using 49 items of the SEEQ. For a total of 380 self-identified TCs they concluded that certain modifications to the traditional TC model are possible without losing the TC model's core technology. However, modifications of the structure or to the intensity of the TC programming did have a significant impact on adherence to the TCs' core characteristics (Dye et al., 2009).

Comparable data from a European study is not available. To our knowledge the SEEQ has not yet been administered in a European sample of TCs. However, in the UK, the quality network "community of communities"1 created "The service standards for European TCs for addiction". Those standards represent developing views on the central elements of TC practice and were primarily developed as an audit and evaluative system for the TCs in the treatment of mental illness and personality disorders (Haigh \& Tucker, 2004). From 2006 till 2007, the service standards were piloted by ten European TCs for addiction. But to date, the results of this research remain unpublished. The aim of the present study is to address previously mentioned research gaps using the abbreviated version of the SEEQ. First, we examined to what extent the

${ }^{1}$ http://www.rcpsych.ac.uk/clinicalservicestandards/centreforqualityimprovement/communityofcommuniti es/servicestandards/addictiontcs.aspx 
European TCs for addiction, both traditional and modified, are in agreement with their American predecessors on what can be considered as 'the essential elements' of the TC. That is, do they all have similar designs, share comparable concepts and beliefs, and engage in similar practices? As mentioned in the introduction, the search for similarities and differences between the two traditions has frequently been the subject of the discourse. Nonetheless, till this day, there is still no scientific evidence to support these claims.

The second aim of this study is to determine to what degree European traditional TCs can be differentiated from the modified TCs. North-American studies have shown that, although some significant variations in adherence to the 'community as method' elements of the traditional TC model could be found, all TCs, traditional or modified, still remain true to the basic elements outlined in De Leon's classic TC model (Dye et al., 2009; Melnick \& De Leon, 1999). Considering previous findings, we expect that the European traditional TCs will demonstrate a higher degree of adherence to the key characteristics of a traditional TC model than the European modified TCs, but that overall they will be more alike than different.

\section{METHOD}

- Sample and data-collection

Europe

The collection of European data occurred from December 2008 until March 2009. Specifically for this study, we targeted West-European TCs which are member of the European Federation of Therapeutic communities (EFTC). An email-survey was distributed to the directors of the different TC programs $(n=38)$ with the support of the EFTC. In attachment we added a brief letter containing the instructions and the general aims of the research study. 
A total of 24 TCs $(63 \%)$ responded, representing 13 of the 14 western-European countries which currently are member of the EFTC. Twenty surveys were completed by the director of the TC programs and four with the help of a senior staff member. Ambulatory programs, halfway-houses, and TC programs with a duration of stay less than six months $(n=5)$ were excluded from the study. The 19 remaining programs varied in expected duration of stay from 6 months to 2 years. Of those 19 TCs, 8 were identified by the first author as modified (4 programs served special target groups and 4 programs had durations of stay between $6-10$ months).

America

American data has been collected by Melnick and colleagues in 1994 (Melnick et al., 2000). For their study, which was published in 2000, they developed a typology of TC treatment, based on the 'Therapeutic Community Survey of Essential Elements Questionnaire (SEEQ), and ultimately extended the results of a previous investigation on the subject (Melnick \& De Leon, 1999). They contacted 19 Long-Term Residential programs who had participated in the Drug Abuse Treatment Outcome Study (DATOS) which took place between 1991 and 1993 in 11 cities throughout the United States. Besides the distribution of the survey, the authors also added a brief vignette containing the expected treatment duration and a set of general treatment goals. By doing so the directors of the different agencies were able to identify whether they were a traditional $(\mathrm{n}=11)$ or a modified TC $(\mathrm{n}=8)(5$ modified TCs have duration of stay between $6-12$ months, 1 has duration of stay less than 6 months)

- Instruments

As mentioned earlier, the Survey of Essential Elements Questionnaire (SEEQ) is based on the theoretical framework of the TC treatment model as described by De Leon (1995). It was further refined with the help of an advisory group, a selected group of $11 \mathrm{TC}$ experts and 1 well experienced researcher. After several extensive reviews by all the members of this group, the SEEQ ultimately contained 135 likert-type items 
organized around 6 broad dimensions and 27 domains. These dimensions represent the different components of TC treatment whilst the domains highlight the modalities' distinctive philosophy and treatment elements. Ratings per item go from $0=$ "no importance" to $4=$ "Extremely important".

For this study a short version of the SEEQ (Melnick et al., 2000) was used. The adaptation of the original form condensed the consolidation of the different items per domain into one statement. For example, the 2 items belonging to the domain 'Role of the Family' were comprised to the following statement: "Where appropriate, the family is included in the treatment plan".

The inter-rater reliability (Cronbach's alpha) for the European and American version of the SEEQ is respectively 0.81 and 0.85 , suggesting an acceptable internal reliability. For an overview of the cronbach's alpha per SEEQ subscales, see table 1 .

Table 1: inter-rater reliability per subscale of the Survey of Essential Elements Questionnaire (SEEQ)

\begin{tabular}{lcc} 
& European study & American Study \\
\hline SEEQ SUBSCALES & \multicolumn{2}{c}{ Cronbach's alpha } \\
TC Perspective & 0.75 & 0.89 \\
The agency: treatment approach and structure & 0.75 & 0.82 \\
Community as therapeutic agent & 0.78 & 0.80 \\
Educational and work activities & 0.85 & 0.80 \\
Formal therapeutic elements & 0.78 & 0.83 \\
Process & 0.77 & 0.82 \\
\hline
\end{tabular}

\section{- Data-analysis}

One way analysis of variance for independent groups (ANOVA) was used to test whether the mean scores of the European TCs on the dimensions and domains of the SEEQ differed significantly from the mean scores of American TCs. ANOVAs were also performed to compare the means of the European modified TCs with the means of the European traditional TCs. 


\section{RESULTS}

As shown in table 2, the analysis indicates that traditional TCs, both in Europe as well as in America, share a fairly comparable view on what is essential in TC treatment. Nevertheless contrarily to what may be expected, European traditional TCs more strongly endorse the 'view of addictive disorders' $(\mathrm{F}(1,19)=7.94$; $\mathrm{p}=0.011)$ and the 'view of the addict' $(\mathrm{F}(1,19)=6.74 ; \mathrm{p}=0.018)$ than their American predecessors. They also put a significantly stronger emphasis on the 'agency approach to treatment' which centers on member's participation $(\mathrm{F}(1,21)=8.3 ; \mathrm{p}=0.009)$ and 'the role of family in treatment' $(\mathrm{F}(1,21)=10.6 ; \mathrm{p}=0.004)$.

With regard to the modified TCs, we did not find any significant differences although comparisons of the mean scores in table 1 suggest that European TCs might be less in agreement about the core TC characteristics as described in the SEEQ than the American TCs.

Finally, comparisons between traditional and modified TCs in Europe show significant differences on 3 SEEQ dimensions and 8 SEEQ domains. More specifically, traditional TCs rated the dimensions 'TC Perspective' $(\mathrm{F}(1,18)=11.3 ; \mathrm{p}=0.004)$, 'TC treatment approach and structure' $(\mathrm{F}(1,18)=9.1 ; \mathrm{p}=0.008)$ and 'TC process' $(\mathrm{F}(1,18)=9.8 ; \mathrm{p}=0.006)$, higher than the modified TCs. With respect to the SEEQ domains, the traditional TCs more strongly emphasized 'the view of the addictive disorder' $(\mathrm{F}(1.18)=7.7 ; \mathrm{p}$ $=0.023)$ and 'the view of the addict' $(\mathrm{F}(1,18)=5.8 ; \mathrm{p}=0.027)$, that is, traditional TCs are more convinced than the modified TCs that 'drug abuse' is not the main problem but rather a symptom of underlying psychological and behavioral disorders. In comparison to the modified TCs, they also paid more attention to educational activities that focus on personal developmental issues' $(\mathrm{F}(1,18)=4.9 ; \mathrm{p}=0.040)$ and to the 'roles and functions of clients' such as the expectation of clients to function as member of the community, reinforce community values and to serve as role models $(F(1,18)=5.6 ; p=0.029)$. In addition, traditional TCs more strongly agreed on the importance of 'peers as gate keepers' $(\mathrm{F}(1,18)=5.0 ; \mathrm{p}=0.040)$ and 'peers' mutual self-help' $(\mathrm{F}(1,18)=4.8 ; \mathrm{p}=0.044)$ as critical components of the recovery process. Finally, traditional TCs assigned greater importance to 'frequent group activities' that reinforce community norms (F 
$(1,18)=4.66 ; p=0.46)$ and to 'the re-entry phase' where they prepare clients for a life in the outside

community $(F(1,18)=5.0 ; p=0.04)$.

Table 2: Responses to the Survey of Essential Elements Questionnaire (SEEQ) by origin and type of TC

\begin{tabular}{|c|c|c|c|c|}
\hline \multirow[b]{2}{*}{ SEEQ dimensions and corresponding domains } & \multicolumn{2}{|c|}{ Western-European TCs } & \multicolumn{2}{|c|}{ American TCs } \\
\hline & Traditional & Modified & Traditional & Modified \\
\hline THE TC PERSPECTIVE** & 3.6 & 3.0 & 3.3 & 3.0 \\
\hline 'Drug abuse' reflects general coping problems $* \infty$ & 3.6 & 2.8 & 3.0 & 2.9 \\
\hline 'Drug abuse' rooted in developmental and psychological problems $* \infty$ & 3.5 & 2.5 & 2.6 & 2.4 \\
\hline 'Recovery' involves global changes in identity, behavior, and lifestyle & 3.8 & 3.3 & 3.6 & 3.4 \\
\hline Right living includes self-reliance and positive attitudes & 3.5 & 3.5 & 3.7 & 3.1 \\
\hline THE AGENCY: TREATMENT APPROACH AND STRUCTURE** & 3.7 & 3.2 & 3.7 & 3.6 \\
\hline Agency follows a daily structured routine & 3.7 & 3.5 & 3.8 & 3.7 \\
\hline Treatment approach is centered on member participation $\infty \infty$ & 4.0 & 3.9 & 3.6 & 3.7 \\
\hline Staff functions as members of the community & 3.6 & 3.0 & 3.8 & 3.6 \\
\hline Clients are members of the community* & 3.7 & 3.1 & 3.8 & 3.7 \\
\hline Educational classes are provided on health-related issues & 3.3 & 2.6 & 3.6 & 3.1 \\
\hline COMMUNITY AS THERAPEUTIC AGENT & 3.4 & 3.0 & 3.6 & 3.4 \\
\hline Peers as gate keepers protect community values* & 3.5 & 3.0 & 3.6 & 3.3 \\
\hline Peers provide mutual self-help* & 3.5 & 2.8 & 3.6 & 3.3 \\
\hline Daily activities emphasize community participation & 3.6 & 3.4 & 3.6 & 3.4 \\
\hline Contact with outside community & 3.8 & 3.0 & 3.1 & 3.6 \\
\hline Community hierarchical organization includes status and privileges & 3.2 & 2.4 & 3.7 & 3.4 \\
\hline Community uses sanctions for norms violations & 3.5 & 3.4 & 3.6 & 3.3 \\
\hline Periodic formal community surveillance & 3.1 & 2.9 & 3.6 & 3.3 \\
\hline EDUCATIONAL AND WORK ACTIVITIES & 3.6 & 2.9 & 3.6 & 3.1 \\
\hline Academic and/or vocational training is available* & 3.5 & 2.3 & 3.3 & 3.0 \\
\hline Life Skills training is available & 3.5 & 3.3 & 3.5 & 3.1 \\
\hline Work is an important part of the therapeutic program & 3.8 & 3.0 & 3.9 & 3.3 \\
\hline FORMAL THERAPEUTIC ELEMENTS & 3.5 & 3.0 & 3.4 & 3.1 \\
\hline Behavior is either reinforced or confronted & 3.4 & 3.1 & 3.7 & 3.4 \\
\hline Frequent group activities reinforce community norms* & 3.5 & 2.9 & 3.6 & 3.4 \\
\hline Counsellors are role models of community norms & 3.5 & 2.9 & 3.5 & 3.7 \\
\hline Family members are included as part of therapy $\infty \infty$ & 3.5 & 3.0 & 2.7 & 2.0 \\
\hline PROCESS $* *$ & 3.7 & 3.2 & 3.6 & 3.5 \\
\hline Phase progression from orientation to primary to reentry & 3.5 & 3.1 & 3.6 & 3.4 \\
\hline Orientation focuses on client assimilating into the community & 3.7 & 3.3 & 3.6 & 3.3 \\
\hline Primary treatment focuses on developing prosocial norms & 3.5 & 3.1 & 3.6 & 3.4 \\
\hline Re-entry prepares client for transient to outside community* & 3.8 & 3.3 & 3.7 & 3.7 \\
\hline
\end{tabular}




\section{DISCUSSION}

This study represents the first attempt to scientifically contribute to the ongoing debate about whether the European and American TCs both operate within the context of comparable principles or rather have developed their own distinct identity. In addition, this study has granted us the opportunity to assess to what extent traditional and modified TCs have remained faithful to the essential elements of a traditional TC model, outlined by De Leon (1995a, 2000).

In reference to the first issue, the findings clearly demonstrate high levels of agreement amongst the European and the American traditional TCs about what constitutes the essential elements of TC treatment. Nonetheless, the results also highlighted a few significant differences. One difference concerns the role of family members in therapeutic community treatment, which appears to be more widely accepted in European traditional TCs than in their American counterparts. A plausible explanation for this difference is the fact that, historically, European traditional TCs relied more on the professional resources of their teams (Soyez et al, 2004). As such, family involvement was easily embedded and integrated within the European TC-context. In Synanon, family relationships were perceived as destructive influences that needed to be avoided. Staff members in the first American TCs initially took over this vision and consequently excluded family members from the treatment. According to Kaufman and Kaufmann (1992) the lack of knowledge of workable family therapy techniques and the staff members their own unresolved anger towards his or her own family of origin, also contributed to family exclusion. After a while, some TCs started organizing conversation groups for relatives. The sole purpose of these groups was to better prepare family members for a first encounter with their relative during re-entry. Some TCs added family therapy to TC treatment in order to solve family problems. However, it was only during the last two decades that family resources were also used to support the addict during the TC treatment process. In general, the TCs' view on family involvement developed from 'total exclusion' (contact with family was prohibited because of their negative influence to the treatment process), to 'partial inclusion' (informal parent meetings, weekly groups for family members, multi-family 
groups), to an 'integrated element' essential to the proper functioning of the TC. As mentioned above, this growing attention for family involvement was mainly the work of professionals (family therapists) who introduced new techniques and humanistic approaches (Soyez et al., 2004).

Analyses of the data also revealed that European traditional TCs give significantly higher endorsements to the TC perspective on recovery and to the basic beliefs that the treatment approach is centered around the participation and engagement of its members. These results are somewhat at odds with the literature that states that, due to their very unique background, European TCs and American TCs should be looked upon as two distinguishable approaches. As a matter of fact, the findings more strongly suggest that European TCs are par with their American predecessors or at least are now on converging pathways. This conclusion is in accordance with Haigh and Lees' premises stating "In the past, the differences were more stark, but changes in the political and social context have influenced the programmes in both main types of therapeutic community... ." Presently, both types of TCs use structured programs, employ professional staff as well as ex-addicts, endorse the 'community as method' as the mode of treatment and highly value the use of groups and peers as therapeutic agents. Although European TCs originated from psychiatry and mainly addressed the treatment of personality disorders whilst the American TCs historically focused on the recovery of addiction, they now serve fairly similar target groups (Haigh and Lees, 2008).

A question that remains unclear however, is whether European and American traditional TCs were ever that different to begin with. For instance, to what extent does our European research sample have its roots in milieu therapy, psychoanalysis and the Maxwell Jones's democratic TC approach? When scrutinizing the literature on the history of European TCs for addiction the authors always seem to refer to the British TC model, which is indeed the cradle of the democratic TC but not necessarily at the root of our European study sample. In an article on the early development of European TC for addictions, Broekaert et al. (2006a) describe how Daytop New York directly influenced programs in Switzerland, Germany, Sweden and Finland and how Phoenix House New York influenced the rest of Europe through Phoenix House London and 
Emiliehoeve in the Netherlands. The authors also demonstrate how, before their introduction to the American model, most of these European TCs became acquainted with Maxwell Jones' democratic TC. For example: in the UK, Phoenix House London, originally called Featherstone Lodge Project, started under the supervision of Griffith Edwards who himself had experimented with a Maxwell Jones democratic TC approach for alcoholics. Yet, it was Dennie Yuson, an ex-addict and ex-resident of Phoenix House New York, who was appointed its first director (Broekaert et al., 2006a). In the Netherlands, Martin Kooyman founded Emiliehoeve based on the principles of Maxwell Jones and changed the program into a drug-free concept TC after having endured some negative experiences with the democratic model (Broekaert et al. 2006a). To cite Kooyman's experience on the matter (2001): "Gradually, with the help of staff and ex-staff members of Daytop Village and Phoenix House, a clear and structured program was developed.”

Our study also revealed an important finding concerning the modified TCs. When comparing the mean scores of the modified European and US programs, we noticed that the European modified TCs were less in agreement about the essential elements of treatment than the American modified sample. Surprisingly, these differences were not significant which might indicate that within the modified samples there are large variations in adherence to the elements of the traditional TC model.

In addition, when comparing the results of the American sample (published by Melnick et al. in 2000) on the differences in SEEQ scores between modified and traditional TCs, with the results of our own European sample, we found significantly more differences. It appears that in our European sample, the traditional TCs scored significantly higher than the modified TCs on three SEEQ dimensions $(n=6)$ and eight SEEQ domains $(n=27)$, whereas in the American sample, the analysis of the SEEQ scores showed only two significant differences and several trends with moderate effect.

The discovery that the differences between traditional and modified TCs are more pronounced in Europe than in America could be a sign that some European TCs are not really modified but should be described as "TCoriented". According to De Leon (2000), TC-oriented programs have implemented some specific ingredients 
of the TC approach next to other evidence-based methods, but in contrast to the modified TC programs, TCoriented programs abandoned 'community as method' as their primary treatment element. However, this finding needs to be replicated with a larger sample because we do not know how well and how faithful these programs have implemented the core elements of the TC approach.

There are a number of other limitations to consider when interpreting the results. First, this study relies on a small sample size which might have caused the lack of statistical significance between the American and European modified TCs. The readers should also be aware that the designation of the European programs as traditional or modified was different from the American study. The European cluster differences were identified by the first author based upon the TCs' length of stay and the population whereas the American cluster differences were identified by the directors of the participating programs. Another factor that might have influenced the statistical significance in this study is the difference in professional affiliation of the respondents who actually filled out the SEEQ. In the European study, fifteen surveys were completed by the program's director and four with the help of a senior staff member compared to the American study where all surveys were rated by the directors themselves.

Secondly, the SEEQ only provides quantitative data on the essential elements of the TC treatment while a qualitative study might give more detailed information on the specificity of the modifications. In addition, the items of the abbreviated survey do not capture subtle differences between programs. For example: the SEEQ item representing the use of confrontational and behavioral modification techniques might be graded as extremely important by both the European and the American traditional TCs while in reality the European TCs have a different idea on the intensity of confrontations.

Notwithstanding the limitations noted above, this study yields evidence for the premise that the TC for addiction is generic. Actually, despite some significant differences, an average score of "very important' to 'extremely important' on five SEEQ domains and seventeen SEEQ dimensions supports the idea that, regardless of their origin, population and length of stay, TCs share a fairly common 
perspective on what is essential in treatment. All TCs subscribe to the same perspective on recovery and right living and strongly adhere to the treatment approach and structure, except for educational classes that focus on health issues. They also view peers as gate keepers that protect community values, manage daily activities to endorse community participation, gradually involve the outside community, and use sanctions for norms violations. In addition, all TC programs obtain clients' social and psychological development through the use of behavior modification techniques, educational classes and work. And, finally, they all share a similar perspective on the TC process, that clients gradually move through three different stages each with their own specific goals and expectations.

The current study also provides proof that the SEEQ can help European TCs determine their fidelity and uphold the quality of their care. On one hand, the instrument allows programs to clearly specify the elements of the TC model that have been implemented as intended while on the other hand it capotes the ability to modify certain components in order to adapt to different populations and settings without abandoning 'community as method'. For European TC researchers, the SEEQ presents an opportunity to generalize findings based on the similarity of elements. Yet, it does not provide evidence of program effectiveness. More comprehensive assessments of the typical components of the TC model and the analysis of what actually occurs during treatment is needed to determine which elements of the TC program are effective in producing positive outcomes. 


\section{REFERENCES}

Alterman, A., Randall, M., \& McLellan, A. (2000). Comparison of outcomes by gender and for fee-for service versus managed care: a study of nine community programs. Journal of substance abuse treatment, 19,127-34.

Broekaert, E., van der Straten, G., D'Oosterlinck, F., \& Kooyman, M. (1999). The Therapeutic Community for ex-addicts: a view from Europe. Therapeutic Communities: The International Journal for Therapeutic and Supportive Organizations, 20, 255-266.

Broekaert, E., Vanderplasschen, W., Temmerman, I., Ottenberg, D., \& Kaplan, C. (2000). Retrospective study of similarities and relations between the American drug free and the European therapeutic communities for children and adults. Journal of Psychoactive Drugs, 32, 407-417.

Broekaert, E., Vandevelde S., Schuyten, G., Erauw, K., \& Bracke, R. (2004). Evolution of encounter group methods in therapeutic communities for substance abusers. Addictive Behaviors, 29,231-244.

Broekaert, E., Vandevelde S., Soyez, V., Yates, R., Slater, A. (2006a). The third generation of therapeutic communities: the early development of the TC for addictions in Europe. European Addiction Research, 12, 1-11.

Broekaert, E. (2006b). What future for the Therapeutic Community in the field of addiction? A view from Europe. Addiction, 101, 1677-1678.

Broekaert, E., Colpaert, K., Soyez, V., Vanderplasschen, W,. \& Vandevelde, S. (2007).Transatlantic dialectics: A study on similarities and dissimilarities in approaches to substance abuse problems in the United States and Europe. International Journal of Therapeutic Communities, 28, 33-44.

De Leon, G. (1995a). Therapeutic communities for addictions: A theoretical framework. International Journal of the Addictions, 30, 1603-1645.

De Leon, G. (1995b). Residential therapeutic communities in the mainstream: Diversity and issues. Journal of Psychoactive Drugs, 27, 3-15. 
De Leon, G. (1997). Community as method: Therapeutic Community for special populations and special settings. Westport, CT: Greenwood Publishing Group, Inc.

De Leon G., (2000). The therapeutic community. Theory, Model, and Method. New York: Springer.

De Leon, G., Sacks, S., Staines, G., \& McKendrick, K. (2000). Modified therapeutic Community for Homeless Mentally ill Chemical Abusers: Emerging Subtypes. American Journal of Drug and Alcohol Abuse, 26, 461-480.

De Leon, G. (2001). Therapeutic communities for substance abuse: developments in North America. In Rawlings, B., Yates, R., (Eds). Therapeutic communities for the treatment of drug users. Pp. $79-104$. London: Jessica Kingsley Publishers.

Dye, M.H., Ducharme, L.J., Johnson, J.A., Knudsen, H.K., \& Roman, P.M. (2009). Modified therapeutic communities and adherence to traditional elements. Journal of Psychoactive Drugs, 43, 275-283.

Haigh, R. \& Lees, J., (2008). Fusion TC's: Divergent histories, converging challenges. Therapeutic Communities, 29, $347-374$.

Haigh, R., \& Tucker, S. (2004). Democratic development of standards: A quality network of therapeutic communities. Psychiatric Quarterly, 75, $263-277$.

Knight, K. Simpson, D.D., Chatham, L.R., \& Camacho, L.M. (1997). An assessment of prison-based drug treatment: Texas' in prison therapeutic community program. Journal of Offender Rehabilitation, 24, 75-100.

Janzen, R., (2001). The Rise and Fall of Synanon: A California Utopia. Baltimore, London: The John Hopkins University Press.

Jainchill, N., Hawke, J., \& Messina, M. (2005). Post-treatment outcomes among adjudicated adolescent males and females in modified therapeutic community treatment. Substance Use and Misuse, 40, 975996. 
Kaufman, E., \& Kaufmann, P. (1992). Family therapy of drug and alcohol abuse. (2 ${ }^{\text {nd }}$ edition). Boston: Allyn and Bacon.

Kennard, D. (1998). An introduction to therapeutic communities. London: Jessica Kingsley.

Kooyman, M., (1992). The therapeutic community for addicts: intimacy, parent involvement and treatment outcome. Rotterdam: Universiteitsdrukkerij. Erasmusuniversiteit.

Kooyman, M. (2001). The history of therapeutic communities: a view from Europe. In Rawlings, B., Yates, R. (Eds.). Therapeutic communities for the treatment of drug users. Pp. 59 - 79. London: Jessica Kingsley Publishers.

Melnick, G., \& De Leon, G. (1999). Clarifying the nature of therapeutic community treatment: A survey of essential elements. Journal of Substance Abuse Treatment, 16, 307 - 313.

Melnick, G., De Leon, G., Hiller, M.L., \& Knight, K. (2000). Therapeutic community: diversity in treatment elements. Substance Use and Misuse, 35, 1819 - 1847.

O’Brien, W.B., \& Hennican, E. (1993). You can't do it alone. New York: Simon and Schuster.

Prendergast, M.L., Hall, E.A, Wexler, H.K., Melnick, G., \& Cao.,Y. (2004). Amity Prison-based therapeutic community: 5-year outcomes. The Prison Journal, 84, 36-46.

Sacks, S., Banks, S., Mckendrick, K., \& Saks, J.Y. (2008). Modified therapeutic communities for cooccurring disorders: A summary of four studies. Journal of Substance Abuse Treatment, 34,112-122.

Soyez, V., Tatrai, H., Broekaert, E., \& Bracke, R. (2004). The implementation of contextual therapy in the therapeutic community for substance abusers: a case study. Journal of Family Therapy, 26, 286-305.

Sugarman, B. (1974). Daytop Village: A therapeutic community. New York: Holt, Winston and Rinehart.

Sugarman, B. (1986). Structure, variations, and context: A sociological view of the therapeutic community. In De Leon, G., Ziegenfuss, J.T. (Eds.). Therapeutic communities for addictions. Readings in Theory, Research and Practice. Springfield, Illinois: Charles C Thomas Publisher. 
Vandevelde, S., Broekaert, E., Yates, R., \& Kooyman, M. (2004). The development of the therapeutic community in correctional establishments: a comparative retrospective account of the 'democratic' Maxell Jones TC and the 'hierarchical' concept-based TC. International Journal of Social Psychiatry, 50, 66-79. 